\section{APLICACIÓN DE LAS NUEVAS TECNOLOGÍAS A LA ENSEÑANZA DE LA GEOLOGÍA}

\author{
José Eugenio Ortiz \\ Trinidad de Torres \\ Isabel Arribas \\ Domingo Martín-Sánchez \\ Departamento de Ingeniería Geológica, E.T.S.I. Minas \\ Universidad Politécnica de Madrid, C/Ríos Rosas 21 \\ joseeugenio.ortiz@upm.es
}

\section{APPLICATION OF NEW TECHNOLOGIES TO THE TEACHING OF GEOLOGY}

\begin{abstract}
Here we present new teaching and learning approaches, and student assignments implemented in subjects related to Geology at the Madrid School of Mines. The main objective is to bring the geological aspects of Nature to students through the use of new technologies, using individual and group techniques. These new approaches have produced an increase in motivation and acquisition of geological knowledge on the part of students, accompanied by an improvement in grades.
\end{abstract}

KEY WORDS: Educational innovation; Geology; new technologies.

\section{INTRODUCCIÓN}

Cuando se plantea la mejora de la enseñanza y el aprendizaje (en cualquier tipo de asignatura) se puede incidir sobre tres aspecto básicos: los contenidos, la metodología y la evaluación. En lo que respecta a los contenidos, los profesores involucrados en la enseñanza de algunas asignaturas de Geología en la E.T.S.I. Minas entendiamos que no era necesario introducir ninguna modificación ya que se estimaba que eran conceptos básicos y fundamentales que no se podían recortar. Por el contrario, sí que se hizo una modificación en la metodología y en la evaluación.

Las asignaturas relacionadas con la Geología que se imparten en las titulaciones de Ingeniería de la E.T.S.I. Minas de Madrid tienen un número considerable de salidas al campo para que el alumno pueda relacionar los conceptos teóricos con lo observable en la Naturaleza. De he-
RESUMEN: En este trabajo se presentan nuevas estrategias y metodologías de enseñanza y aprendizaje, y tareas de los estudiantes implementadas en asignaturas relacionadas con la Geología de la E.T.S.I. Minas de Madrid. El principal objetivo es acercar los aspectos geológicos de la Naturaleza (Geología) a los estudiantes mediante el empleo de nuevas tecnologías, empleando técnicas individuales y grupales. Se ha observado una mayor motivación y adquisición de conocimientos geológicos por parte del alumnado, que ha llevado aparejado una mejora en las calificaciones.

PALABRAS CLAVE: Innovación educativa; Geología; nuevas tecnologias.

cho, hay una asignatura obligatoria en $3 .^{\circ}$ de I. Geológica denominada Prácticas de Geología y otra optativa en I. Minas e I. Geológica Ilamada Prácticas Geológicas, que se desarrollan en el campo. No obstante, sería deseable realizar un mayor número de prácticas en campo, aunque debido a las limitaciones presupuestarias y, sobre todo, a la limitación temporal de los créditos de las asignaturas, no es posible. Para paliar esta situación y mejorar la calidad de la docencia se desarrolló el proyecto "Aplicación de nuevas tecnologías a la mejora de la calidad de la docencia en asignaturas de la E.T.S.I. Minas" amparado por la convocatoria de Innovación Educativa de la UPM 2010. Las asignaturas en las que se introdujeron cambios en la metodología y aprendizaje fueron:

- Ingeniería de Minas (Plan 1996): "Geología" 1.º obligatoria, 9 créditos; "Estratigrafía, Sedimentología y Análisis de Cuencas" 4. ${ }^{\circ}$ optativa, 6 créditos; "Geología Estructural" 4. ${ }^{\circ}$ optativa, 6 créditos. 
- Ingeniería Geológica (Plan 2000): "Geología General", 1. ${ }^{\circ}$ obligatoria, 6 créditos; "Estratigrafía y Paleontología", 2., obligatoria, 6 créditos; "Geomorfología", 2., obligatoria, 6 créditos; "Geología Estructural", 2. ${ }^{\circ}$ obligatoria, 6 créditos.

- Ingeniería Técnica de Minas (Plan 2002): "Fundamentos Geológicos de la ingeniería", 1., obligatoria, 12 créditos.

\section{Objetivos}

Ante estas circunstancias, el objetivo básico fue el acercar la Naturaleza al alumno a través de las nuevas tecnologías. Para ello se desarrollaron diversas técnicas de enseñanza y aprendizaje individuales y grupales, siempre empleando imágenes geológicas. Cabe destacar que esta nueva metodología está basada en el aprendizaje activo (trabajo del alumno) y que potencia enseñanza práctica, tal y como requieren los nuevos Títulos de Grado según las nuevas directrices del Espacio de Enseñanza de Educación Superior (EEES), aunque los resultados que se presentan en este trabajo se obtuvieron en asignaturas de los planes de estudio previos.

Como resultado básico y principal que se pretendía obtener de los cambios introducidos se encuentran lograr una mayor motivación del alumnado y, fundamentalmente, la mejora del aprendizaje y una mayor y mejor adquisición de los conocimientos relacionados la Geología.

\section{Desarrollo}

A la hora de introducir los cambios en las asignaturas, hay que tomar siempre como referencia los objetivos generales que se pretenden obtener con los alumnos en cada una de ellas y que están marcados en las fichas. En el caso de las asignaturas impartidas en E.T.S.I. Minas de Madrid presentadas en este trabajo, de forma general son los siguientes: 1) Obtener una visión general integrada de la Geología y sus aspectos particulares en cada una de las diferentes ramas; 2) Obtener un cuerpo de conocimientos básicos perfectamente descritos; 3) Obtener una visión muy clara de los elementos comunes a las diferentes ramas de conocimiento que componen la Geología, con preferencia a los diferenciadores; 4) Adquirir un léxico geológico correcto, siendo deseable que conozcan la terminología anglosajona, que hoy día es dominante en artículos, libros especializados, libros de texto y libros de divulgación; 5) Adquirir capacidad de comprensión de artículos o libros que desarrollan con mayor amplitud los temas; 6) Tener una bibliografía básica actualizada.

Partiendo de esta referencia, primeramente cabe mencionar que los cambios introducidos en la metodología estuvieron acompañados de la obligatoriedad de la asistencia a clase y la realización de ejercicios que con el sistema anterior eran voluntarios $y$, en ocasiones, no realizaban. En definitiva, para que la implantación de los nuevos aspectos metodológicos tuvieran un desarrollo óptimo, se introdujeron cambios en la forma de evaluar. De hecho el alumno muchas veces antes que preguntarse cuáles son los conocimientos básicos que debe adquirir al cursar una determinada asignatura, lo que se plantea es cómo va a ser evaluado para, en función de esta respuesta, saber qué, cómo y cuándo tiene que estudiar. En este sentido el aprendizaje podría no verse consolidado por culpa de una evaluación mediocre. De esta manera, se aplicó un sistema de evaluación continua, aunque en algunas asignaturas ("Estratigrafía y Paleontología" y "Geomorfología" de 2. I. Geólogo) ya se habían implantado con anterioridad. Ello fue debido a que, en ocasiones resultaba complicado la transmisión del conocimiento teniendo en cuenta la actitud de algunos alumnos de $2 .^{\circ}, 3^{\text {er }}$ o $4 .^{\circ}$ curso que, en un número importante (25-30\%), practicaban un absentismo a las clases, debido a una mala autoprogramación, que les impedía a matricularse en cursos superiores con una carga importante de asignaturas pendientes de cursos precedentes.

En lo que se refiere a los principios metodológicos (procedimientos y estrategias empleados para ayudar al alumno en la construcción de su pensamiento) que tienen como objetivo "enseñar a aprender", y que se basan principalmente en el trabajo personal del alumno, se introdujeron importantes modificaciones. Aunque ya se venian empleando medios de apoyo actualizados y una metodología que fomentaba la práctica, todo ello basado en estudios (Sáenz y Mas, 1979) sobre la forma en que se realiza el aprendizaje (83\% mediante la vista, frente a un 11\% mediante el oído) y del porcentaje de datos retenidos por los 
estudiantes (10\% de lo que leen, $20 \%$ de lo que escuchan, $30 \%$ de lo que ven, 50\% de lo que ven y escuchan, $70 \%$ de lo que se dice y se discute, $90 \%$ de lo que se dice y luego se realiza), se han introducido nuevas herramientas tecnológicas, como se hace necesario en el EEES, tales como el empleo de la plataforma moodle en la enseñanza virtual. No obstante, cabe destacar que estos cambios se han realizado en asignaturas de las Titulaciones de I. Minas, I. Geológica e I. Técnica de Minas de los planes anteriores a las nuevas Titulaciones de Grado que iniciaron su andadura en el año 2010/2011 con el primer curso, aunque no será hasta el 2011/12 cuando se impartirán en segundo curso las nuevas asignaturas de Geología de acuerdo a las directrices del EEES. Dados los buenos resultados obtenidos que se presentarán en este trabajo, los cambios introducidos se aplicarán asignaturas relacionadas con la Geología en los nuevos Grados. Algunos ejemplos previos de adaptación de asignaturas relacionadas con la Geología a las exigencias de los créditos ECTS como paso previo al cambio al que se ven abocadas se describen en Pascual y Murelaga (2007), Pascual, Murelaga y Oñate (2008) y Tent-Manclús (2008), aunque inciden fundamentalmente en el reparto de clases y en el cambio del sistema de evaluación.

En el desarrollo de la nueva metodología se elaboró, entre otras cosas, una amplia base de imágenes geológicas catalogadas por temática para utilizar tanto en las clases presenciales (teóricas y prácticas) pero, sobre todo, en ejercicios de auto-evaluación desarrollados en la plataforma moodle, o en cuestionarios sobre aspectos de la asignatura. En las clases se introdujeron técnicas de enseñanza como el "brainstorming", "diálogo simultáneo o cuchicheo" y "puzzle" modificado para trabajar sobre las imágenes. En todos los casos (moodle y ejercicios de clase) el alumno dispuso de las respuestas correctas para poder conocer los aciertos y errores.

Con el objetivo de mostrar al profesorado, especialmente de Geología, un ejemplo de adaptación al nuevo sistema del EEES, presentamos la metodología empleada y los resultados obtenidos en la E.T.S.I. Minas de Madrid.

\section{Resultados}

Primeramente se elaboró una base de fotografías geológicas que están catalogadas según su temática: 1) Petro- logía: petrología ígnea, petrología sedimentaria, petrología metamórfica; 2) Geología Estructural: pliegues, fallas, diaclasas; 3) Estratigrafía y Sedimentología: estructuras sedimentarias, discontinuidades, bloques-diagrama sobre Historia Geológica; 4) Geomorfología: glaciar, periglaciar, fluvial, eólica, costera, tropical, relieve granítico, relieve kárstico, relieve volcánico, relieve estructural, tipos de suelos.

La mayor parte de las diapositivas se recopilaron de entre las colecciones de los diferentes profesores, así como de sitios especializados de internet y siempre citando la fuente. Otra parte de estas diapositivas se tomaron de programa Google Earth en donde, a partir de una exhaustiva selección de lugares del Planeta, se capturaron imágenes tomadas desde diferentes perspectivas en las que se observan aspectos geológicos. Asimismo, otra parte de las imágenes fueron tomadas por satélites de la NASA y están a disposición del público en general.

Una de las novedades ha sido elaborar cuestionarios en la plataforma moodle con preguntas concretas cerradas sobre aspectos geológicos de imágenes de la Naturaleza (Fig. 1) en diversas asignaturas (Geología, Estratigrafía y Paleontología, Geomorfología) que los alumnos han podido ya utilizar a lo largo del curso 2010/11. Algunos de estos cuestionarios eran de auto-evaluación, sirviéndole al alumno para una primera toma de contacto previa a la evaluación, mientras que otros contribuían a la nota final. En los cuestionarios de auto-evaluación el alumno, además de obtener la nota global cuando cerraba el cuestionario, podía consultar las respuestas correctas y así comprobar los errores cometidos. Posteriormente, el alumno podía plantear dudas de forma individual o en grupo asistiendo a las tutorías.

Cabe mencionar que, aunque los ejercicios de autoevaluación no contribuian a la nota final, eran de carácter obligatorio. Esto estuvo motivado porque se venía comprobando en años anteriores que aunque se proponían ejercicios, trabajos y exámenes parciales voluntarios, cuya realización suponía un incremento de la nota final y nunca valorándose de forma negativa, había alumnos que no los realizaban y otros que los resolvían pero sin haber realizado un estudio previo. En nuestra opinión esto ha sido un punto clave por un lado, para la motivación del alumnado, que muchas veces aunque se sentía atraído e interesado 


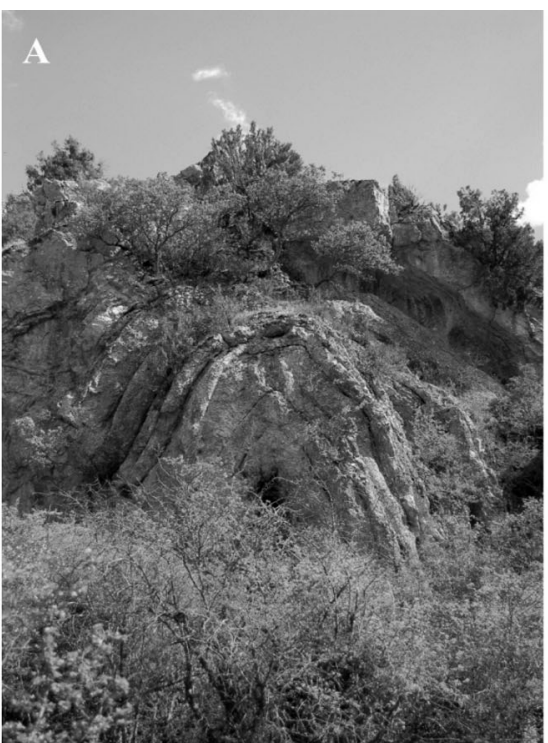

¿Qué tipo de estructura geológica se observa en la imagen?

\ Anticlinal simétrico $\square$ Pliegue recumbente o $\square$ Anticlinal asimétrico acostado

$\square$ Sinclinal simétrico

$\square$ Sinclinal asimétrico $\square$ Falla normal

$\square$ Anticlinal volcado

$\square$ Falla inversa

Sinclinal volcado

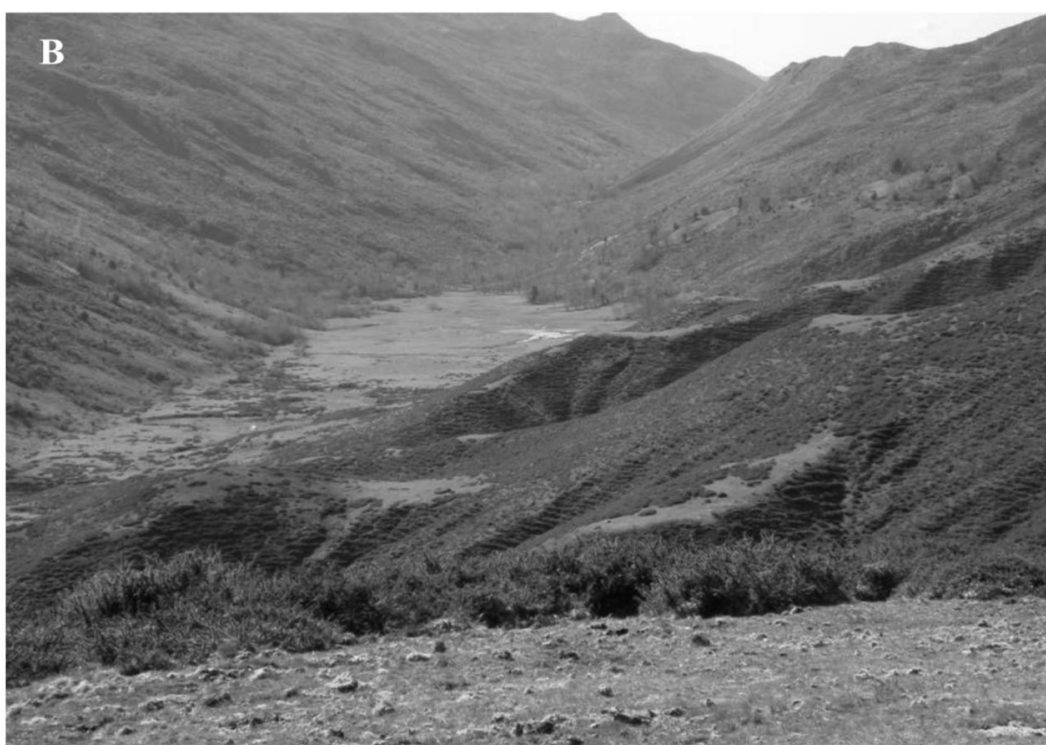

¿Qué tipo de forma/s kárstica/s se observa/n en la imagen?

$\begin{array}{ll}\square \text { Lapiaz } & \square \text { Estalactita } \\ \square \text { Dolina } & \square \text { Estalagmita } \\ \square \text { Valle ciego } & \square \text { Columna } \\ \text { 囚 Polje } & \square \text { Sima } \\ \square \text { Karst de mogotes } & \square \text { Tormo }\end{array}$

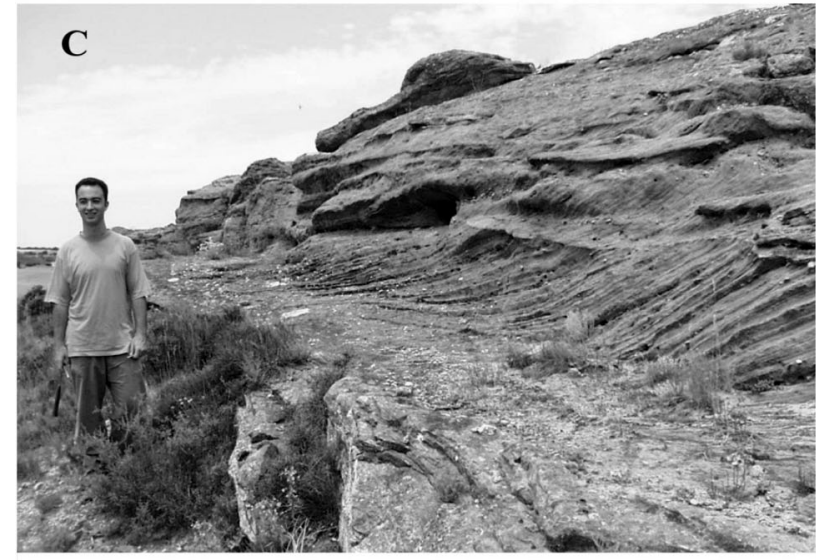

¿Qué tipo de estructura/s sedimentaria/s se observa/n en la imagen?

区. cruzada en surco $\square$ Grietas de desecación $\square$ Laminación paralela

E. cruzada planar

$\square$ E. sigmoidal

$\square$ Ripples

$\square$ Canal

$\square$ Slump

Huellas de objetos

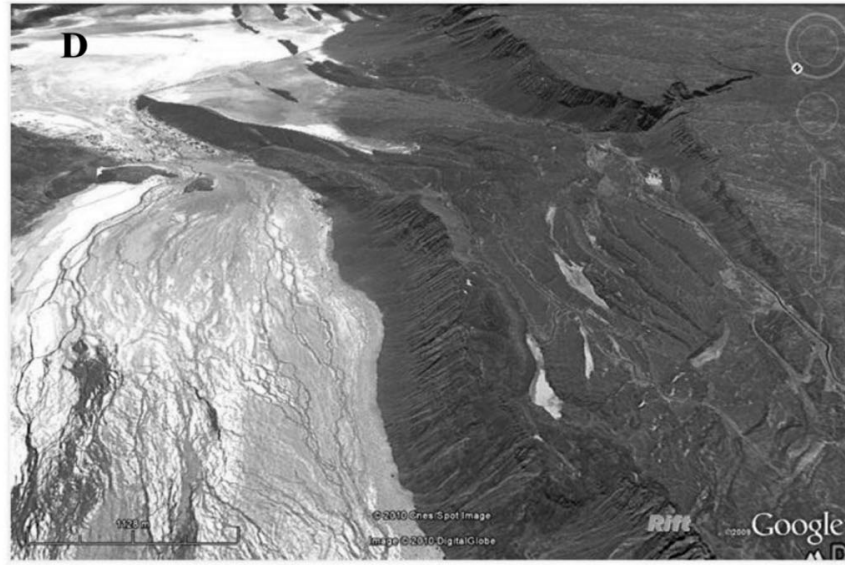

¿Qué tipo de forma estructural se observa en la imagen?

$\square$ Cluse
$\square$ Hog-back
$\square$ Cuesta
$\square$ Crestón
$\square$ Mont
$\square$ Val

$\square$ Combe

$\square$ Cre

$\square$ Ruz

$\square$ Diaclasado $\square$ Domo

$\square$ Chevron

$\square$ fallas de cizalla

\ Fosa tectónica (horst y graben)

Figura 1. Ejemplos de preguntas sobre aspectos geológicos y sus posibles respuestas desarrolladas como ejercicio de autoevaluación en la plataforma moodle. 
por la asignatura, no realizaba los ejercicios propuestos por falta de iniciativa personal dejando el estudio de la materia explicada para pocos días antes del examen final o por dedicación a otras asignaturas.

En clases presenciales ya se venía empleando desde hace varios años la proyección de imágenes geológicas como parte de la explicación del profesor para ayudar al alumno a la mejor compresión de los temas. Como novedad, en este curso se han introducido técnicas de enseñanza grupales basadas en ejercicios sobre imágenes con aspectos geológicos. En la mayor parte de los casos se dividían a los alumnos por grupos establecidos al principio del curso, nombrándose un portavoz diferente cada vez. Se proyectaban tandas de 10 imágenes que los alumnos tenían que discutir por grupos ("diálogo simultáneo o cuchicheo") para después indicar, no sólo la forma o estructura geológica que aparecía en la diapositiva, sino el mecanismo de su génesis. De esta manera al alumno le servía como repaso y adquisición de conocimientos. En ocasiones, cada componente del grupo ganador tuvo un premio material (un mineral o fósil, en cualquier caso, siempre relacionado con Geología), lo que tenía un doble objetivo: motivar a los alumnos y que, al menos los ganadores, recordaran el nombre del fósil o mineral y el grupo al que pertenecen y conozcan su génesis.

En otras ocasiones se utilizó la técnica del "brainstorming" para que el alumno contestara qué forma o estructura geológica se estaba proyectando. En todos los casos el profesor dio las respuestas correctas, abriéndose un diálogo con los alumnos sobre las dudas que se pudieran presentar. A veces se empleó la técnica del "puzzle", aunque con modificaciones. En este caso, era cada miembro del grupo el que tenía que explicar al resto de componentes la forma o estructura geológica de cada diapositiva, estando sometido a sus preguntas y a posibles correcciones.

Además de observar una mayor motivación del alumnado (incluso, en algunas asignaturas llegaron a solicitar la realización de más cuestionarios en la plataforma mo- odle), también se han tenido mejores resultados en las calificaciones, lo que indica una mejor adquisición de los conocimientos.

De hecho, las encuestas propias entregadas a los alumnos para que evaluaran las nuevas metodologías empleadas, revelaron un alto grado de satisfacción con los cuestionarios de autoevaluación y evaluación en la plataforma moodle empleando imágenes con aspectos geológicos. Asimismo, valoraron muy positivamente la realización de estos ejercicios ya que indicaron que les había servido para la adquisición de conocimientos y mejorar la comprensión de la asignatura (media de 9 sobre 10), a pesar de que según su criterio las preguntas no habian sido fáciles, aunque tampoco excesivamente complicadas (media de 5 sobre 10$)$.

No obstante, el mejor sistema para determinar el éxito o fracaso de los cambios introducidos es comparando los resultados de la evaluación de los alumnos al final del curso con los obtenidos en la misma asignatura pero en cursos anteriores. Sirva como ejemplo el de la asignatura de Estratigrafía y Paleontología de la que se venía teniendo un seguimiento desde hace 5 años. Los buenos resultados del uso de imágenes geológicas en clases de teoria ya se había observado en el desarrollo de la asignatura de Estratigrafía y Paleontología (2. I. Geológica) en el curso 2009/10 (Fig. 2) aunque en este caso también se habian introducido cambios en otros aspectos como el sistema de evaluación (Ortiz, Torres y Mansilla, 2010). Como se observa en la Figura 2 el porcentaje de alumnos aprobados que ya había aumentado considerablemente en el curso 2009/2010, se ha incrementado en el curso 2010/2011, destacando el gran incremento de los que tienen una calificación de notable y sobresaliente. Quizá lo más significativo de los cambios introducidos, en nuestra opinión, es la reducción del número de alumnos que abandonaban la asignatura (los "no presentados"), desde el curso 2009/2010 que han resultado favorecidos con el sistema de la obligatoriedad de asistencia y la evaluación práctica. 


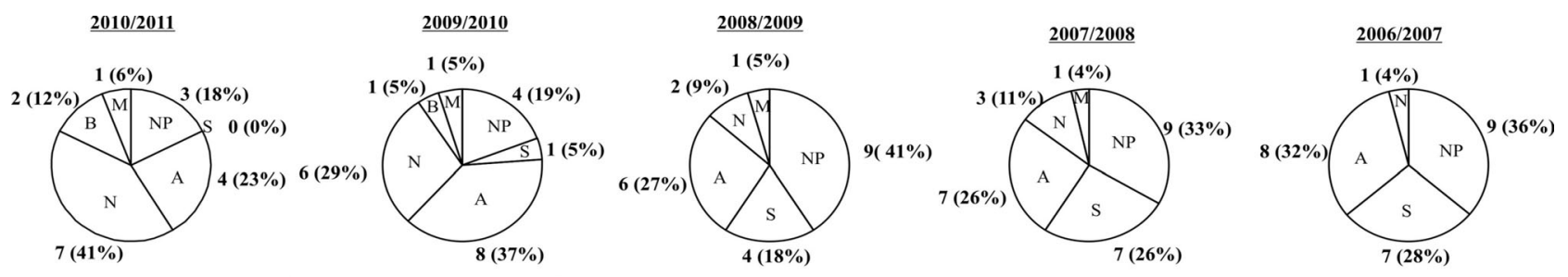

Los números de cada porción de los diagramas circulares corresponden a los alumnos y entre paréntesis aparece el porcentaje sobre el total NP: no presentado, S: suspenso; A: aprobado; N: notable; B: sobresaliente; M: matrícula de honor

Figura 2. Estudio comparativo de las calificaciones finales obtenidas por los alumnos en la asignatura de Estratigrafía y Paleontología en diversos cursos.

\section{ConClusiones}

El empleo de imágenes geológicas en clases presenciales teóricas, pero sobre todo en clases prácticas aplicando técnicas de enseñanza grupales e individuales $y_{1}$ fundamentalmente, a partir de cuestionarios de auto-evaluación en la plataforma moodle, ha favorecido la adquisición de los conocimientos por parte de los alumnos, evidencia que se ha visto reflejada en los resultados de su evaluación. La estrategia metodológica ha supuesto una mejora en los siguientes aspectos:

- Incremento de la motivación del alumno, a partir del acercamiento de los aspectos geológicos que se observan en la Naturaleza, y estableciendo conexiones entre la enseñanza y el entorno vital.
- Personalización de la adquisición de conocimientos y flexibilización de la organización de la enseñanza.

- Control del proceso educativo mediante autoevaluación y evaluación continua.

Dados los buenos resultados obtenidos en la introducción de estas nuevas metodologías de aprendizaje empleando imágenes geológicas, se pretende aplicarlas también a las asignaturas de las nuevas relacionadas con la Geología de las titulaciones de Grado. Cabe destacar también que aunque lo que se ha presentado en este trabajo está aplicado a asignaturas de temática geológica impartidas en la E.T.S.I. Minas de Madrid, se puede aplicar a asignaturas similares en de otras Titulaciones de Geología e, incluso, a otras asignaturas de diferente temática.

\section{BIBLIOGRAFÍA}

Ortiz, J. E.; Torres, T. y Mansilla, H. (2010): "Experiencias educativas en la adaptación de la asignatura Estratigrafía de la titulación de Ingeniería Geológica de la E.T.S.I. Minas de Madrid al Espacio Europeo de Educación Superior (EEES)", Fundamental, vol. 16, pp. 205-212.

Pascual, A. y Murelaga, X. (2007): “Experiencia sobre la adaptación de la asignatura 'Paleontología general y de invertebrados' al Espacio Europeo de Educación Superior", Geogaceta, vol. 42, pp. 99-102.
Pascual, A.; Murelaga, X. y Oñate, L. (2008): "Estrategias didácticas para la enseñanza y el aprendizaje de competencias en 'Geología marina' dentro del Espacio Europeo de Educación Superior", Geogaceta, vol. 44, pp. 135-138.

Sáenz, O. y Mas, J. (1979): Tecnología educativa. Manual de medios audiovisuales, Edelvives, Madrid.

Tent-manclús, J. E. (2008): "Los créditos ECTS en la carrera de Ingeniero Geólogo de la Universidad de Alicante: el trabajo del alumno en la asignatura Técnicas Cartográficas", Geo-Temas, vol. 10, pp. 67-70. 